\title{
DNA Insertion Elements
}

National Cancer Institute

\section{Source}

National Cancer Institute. DNA Insertion Elements. NCI Thesaurus. Code C450.

A short DNA sequence found in prokaryotic and some eukaryotic genomes that encodes proteins involved in DNA transposition and is usually flanked by inverted repeats. 